\title{
Structural Analysis of the Dynamics of Petrochemical Cluster of Republic Tatarstan
}

\author{
Safiullin M.R. \\ Kazan Federal University, Institute of Management, Economics and Finance, Kazan, 420103, Russia
}

Safiullin A.R.

Kazan Federal University, Institute of Management, Economics and Finance, Kazan, 420008, Russia

Email: safiullin.ar@gmail.com

\section{Doi:10.5901/mjss.2014.v5n24p300}

\section{Abstract}

The article analyzes the competitive position and the dynamics of indicators of a petrochemical complex of Republic of Tatarstan. The authors of the article place emphasis on competitive growth of regional commodity producers and the tools applied to evaluate economic efficiency of resources utilization. The article deals with the assessing the level of competition and study the dynamics of the volume turnover. It involves a structural decomposition of growth on sectoral and regional components. The special attention is given to the analysis of costs by kinds of the economic activities, corresponding to an industrial profile of Republic Tatarstan.

Keywords: industrial systems, petrochemical cluster, types of economic activities competitive positions, structural decomposition

\section{Introduction}

Petrochemical and gas cluster of the Tatarstan Republic is the basic sector of the Tatarstan industry forming about 51.9 $\%$ of the total output, $86 \%$ profit, $28 \%$ of the employed. The complex plays a crucial part in foreign trade providing up to $91 \%$ of the total Tatarstan export. The complex combines enterprises the business line of which is resource output, its processing, manufacture of petrochemical and chemical production and final processing production. Four enterprises of the Republic - "Tatneft" JSC, "Nizhnekamskneftekhim" JSC, "Nizhnekamskshina" JSC and "Kazanorgsintez" JSC provide $93.95 \%$ of the total sales of the main petrochemical and gas complex companies and are local economic mainstays of Tatarstan.

The subjects of inquiry within the data base of 2008-2011 have included economic activities from the following sections of the Russian National Classifier of Economic Activities (OKVED): Section C. Mining operations (1 economic activity), Section D. Processing manufactures (5 economic activities).

The research has embraced 63 subjects of the Russian Federation in the following districts: the Central Federal District (18 regions), the Northwestern Federal District (10 regions), the Southern Federal District (4 regions), the North Caucasian Federal District (1 region), the Volga Federal District (14 regions), the Urals Federal District (4 regions), the Siberian Federal District (12 regions). Due to the socio-economic situation, the geographical peculiarities and the branch specialization the research has not covered the regions of the Far Eastern Federal District and the North Caucasian Federal District (except for Stavropol Krai).

\section{Methodology}

According to complex theoretical regulations and methodological instruments of competitive strength analysis applied in modern competitive strength analysis procedures, we have offered a conceptual approach to territory's competitive position study by types of economic activity (TEA) and their competitive edge diagnosis based on labour productivity [5], $[6]^{1}$. Taking into account significant influence exerted by technological peculiarities and market industry-specific factors on competitive positions of types of activity, it seems impossible to express all elements of competitive strength through quantitative indicators within the framework of the present paper.

It seems more reasonable to use OKVED classifier (All-Russian Classifier of Types of Economic Activity) including 14 sections, with subsequent specification, when choosing a competitive profile. 
Determination of critical indicator values is a rather complicated methodological task. As a rule, a certain scope of retrospective information reflecting the phenomenon development experience of the past [7] is required to complete this task. Taking into consideration instability of business environment and competitive strength factors, as well as specific features of technological processes existing in various branches of industry, it is more preferable to set interval threshold values for indicators, from our point of view. Structural decomposition of indicator dynamics permits to differentiate them by uncertainty levels and degree of controllability.

Essence of this method is structural representation of the studied index dynamics [9]. Its increment is resolved into a national component (reflecting trends in the national economy), industrial component (peculiar features of industrial sector development) and territorial component (influence of territorial peculiarities). Correlation between these components permits to distribute types of economic activity by external and internal sources of competitive edges.

If the national component share exceeds that of the industrial and territorial components, it means that the index increment within the analysed period is mainly ensured by a favourable macroeconomic dynamics. In these circumstances industry-specific and territorial trends are of retarded nature. Stability of such a positive increment pattern within a prolonged period of time testifies a rather low strategic potential of these types of economic activity.

In the situation when the industrial component outstrips the national and territorial components, that is, the industry-specific increment displays maximum dynamics; such types of economic activity can serve as possible industrial priorities. In this case competitive edges are formed to a greater extent by virtue of external factors (pricing environment, solvent demand, new technologies, stimulating initiatives at the federal level and others). If such a positive increment pattern persists for a long time, then, in the absence of limitations conditioned by territorial peculiarities, we recommend to consider the aforesaid types of economic activity as strategic guidelines for industrial policy at the mesolevel.

The most attractive is a situation when the territorial component dominates in the index increment pattern. Such a state of affairs allows us to assume presence of internal sources of competitive edges, which ensure that dynamics observed in types of economic activity representing the industrial complex of the territory, outstrips macroeconomic and industry-specific growth rates. A growing share of the territorial component in the positive increment pattern is a target indicator of efficiency of regulatory impacts, which stimulate competitive strength of such types of economic activity that act as a basis for a competitive profile of the territory.

The general formula for calculations is as follows:

$\Delta T_{j}=N S+N I S+R I S$

where NS - national growth component; NIS - industrial growth component; RIS - territorial growth component.

Calculation of each component by shipped products volume is made in the following way:

$$
\begin{aligned}
& N S=v_{j}^{t-1}\left(\frac{V^{t}-V^{t-1}}{V^{t-1}}\right), \\
& N I S=v_{j}^{t-1}\left(\frac{V_{j}^{t}-V_{j}^{t-1}}{V_{j}^{t-1}}-\frac{V^{t}-V^{t-1}}{V^{t-1}}\right) \\
& R I S=\Delta T_{j}^{l}-N S-I S=v_{j}^{t-1}\left(\frac{v_{j}^{t}-v_{j}^{t-1}}{v_{j}^{t-1}}-\frac{V_{j}^{t}-V_{j}^{t-1}}{V_{j}^{t-1}}\right),(4)
\end{aligned}
$$

where $v_{j}^{t}$ and $v_{j}^{t-1}$-shipped products volume in the $j$-th type of economic activity of the territory within the periods $t$ and $t-1 ; V^{t}$ and $V^{t-1}$-industrial products volume shipped in the whole country within the periods $t$ and $t-1 ; V_{j}^{t}$ and $V_{j}^{t-1}$ industrial products volume shipped in the $j$-th type of economic activity within the periods $t$ and $t-1$, correspondingly.

When the dynamics of industrial products volume shipped within the territory exceeds industry-specific growth rates, the territorial component RIS needs modification:

$$
R S=v_{j}^{t-1}\left(\frac{v_{j}^{t}-v_{j}^{t-1}}{v_{j}^{t-1}}-\frac{v^{t}-v^{t-1}}{v^{t-1}}\right),
$$

where $v^{t}$ and $v^{t-1}$-industrial products volume shipped in the territory within the periods $t$ and $t-1$.

Thus, if growth rates of the j-th type of economic activity exceed macroeconomic, industry-specific and regional dynamics of industrial production in a certain territory (especially if the current trend has a clearly defined long-term nature), one can make a conclusion that there are certain competitive edges, which permit us to consider such a type of economic activity as a potentially attractive (target) for further development of the territory under consideration. A complete set of target TEAs can serve as an object of industrial policy at the mesolevel.

While analyzing competitive positions, substantial role plays calculation of concentration and localization indexes 
that allow defining structure of competition on branch markets to which the selected types of economic activity belong [1], [3].

According to the theoretical analysis, three following primary characteristics of branch markets are singled out in the economic literature: concentration, scale and product differentiation [2]. Apart from the fact that each of them has its own functional value, their diverse combinations influence the specificity of branch structure in a complex manner. For instance, product differentiation and concentration influence intra-branch manufacturers' competition in prices and profit margins [8]. Economy of scale, product differentiation and related to it adherence to conventional brands define new entry possibility, as well as opportunities to maintain higher prices not to attract external competition. Three elements provide monopolistic advantages establishing market entry-quit barriers. In this respect, the structure can define not only the highest price set without threat of quitting the market, but also the opportunity for existing manufacturers future collaboration in order to achieve this maximum price avoiding price competition between them. Besides, if product differentiation can serve as the only one barrier to enter the branch market, concentration and economy of scale have closer tie and act jointly. In this connection, while managing competitive edges on branch markets it is required to pay attention to self- analysis of not only these factors economic content, but also to interrelation between them.

Thus, production concentration reflects relative value and number of branch market manufacturers. The fewer the number of manufactures is the higher is concentration level. If the number of manufacturers the same, the situation is the following: the less they differ from each other in size, the smaller is concentration level. Result of manufacturer selfselection on production capacity and price is formed by feedback of market acting competitors. Concentration level impacts the manufacturers' disposition to competition and collaboration: the fewer manufactures on market are, the easier they understand mutual dependence and sooner accept cooperation.

Therefore one can suppose that the higher concentration level is, the more competitive and monopolistic will be the market.

Since 1982 the United States Department of Justice has used the Herfindahl-Hirschman index (HHI) as the main characteristics for branch markets structure. This index is defined as the sum of squares of shares of shipped goods volumes in each region (territory) on branch market:

$$
H H I=\sum_{n=1}^{N} S_{n}^{2}
$$

where $S_{n}$ - industry share in n-territory in total volume of shipped goods countrywide.

If the index value is between 0 and 1000, the market is considered to be weakly concentrated, between 1000 and 1800 - moderately concentrated and more than 1800 - highly concentrated.

While analyzing branch markets structure on meso-level the concentration index should be supplemented by the localization factor:

$$
I_{L j}=\frac{D_{j k n}}{D_{j k}}
$$

where $I_{L j}$ - localization factor of industrial production of j-type of economic activity in n-territory; $D_{j k n}$ - share of shipped products of j-type of economic activity in total volume of shipped goods under k-chapter of the Russian classification system of types of economic activities $(\mathrm{k}=1 ; 6)$ or in industry in $\mathrm{n}$-territory in whole; $D_{j k}$ - share of shipped goods of j-type of economic activity in total volume of shipped goods under k-chapter of the Russian classification system of types of economic activities $(\mathrm{k}=1 ; 6)$ or in industry countrywide.

If the estimated values of a factor are more than 1, then the given type of economic activity appears to be core for the territory with its competitive edges and potentially attractive for further development (if it is 1 - the type of economic activity satisfies only local demand and is focused on internal market). If localization factor acquires the value less than 1 - the territory specializes in this type of economic activity, the internal demand mostly replaced by import from other territories.

Estimation of localization factor dynamics is reasonable: its growth can testify strengthening of its competitive edges on branch markets and favorable prospects of development, its decrease evidences competition sharpening or market situation decline that require expansion of competitive edges, diversification of production factors to enter the adjacent markets or decrease of business activity in this type of economic activity [4].

Localization factor can be estimated either by indicators absolute values (gross value added, number of enterprises, main production foundations, amortization, salary budget, amount of employed, investments to fixed capital) or by growth rates. For instance, estimation of localization factor by the number of employed can be made in the following manner: 


$$
I_{L j}^{l}=\frac{l_{j n} / l_{n}}{L_{j} / L}
$$

where $l_{j n}$ - number of employed in j-type of economic activity in n-territory; $I_{n}$ - number of employed in industry in nterritory; $L_{j}$ - number of employed in j-type of economic activity countrywide; $L$ - number of employed in industry countrywide.

One can calculate the given indicators on the example of analysis of competitiveness types of Tatarstan economic activities in terms of the Russian Federation regions, by means of study of production efficiency indicators of petrochemical cluster.

\section{Results}

This sampling has allowed covering the main economic activities of the Tatarstan Republic having the greatest share in the total turnover of organizations (without VAT, excises and similar obligatory payments). The most appreciable share (over $2 \%$ ) in the total turnover of the Tatarstan Republic among the chosen economic activities was occupied by:

- extraction of crude oil and casinghead gas; extraction of fractions from casinghead gas (16.76 \%);

- petroleum refinery $(5.50 \%)$;

- $\quad$ synthetic rubber production (5.35\%);

- plastic and initial form synthetic resins production (2.16\%).

In the period of $2007-2010$ the following types of economic activity of Tatarstan petrochemical cluster increased their market share: production of synthetic rubber, production of rubber tires, tire casings and inner tubes, production of soap and detergents, extraction of crude oil and oil (associated) gas, production of plastics. Besides, market share of plastics and synthetic resin production as well as petroleum production was prominently decreased (Fig. 4).

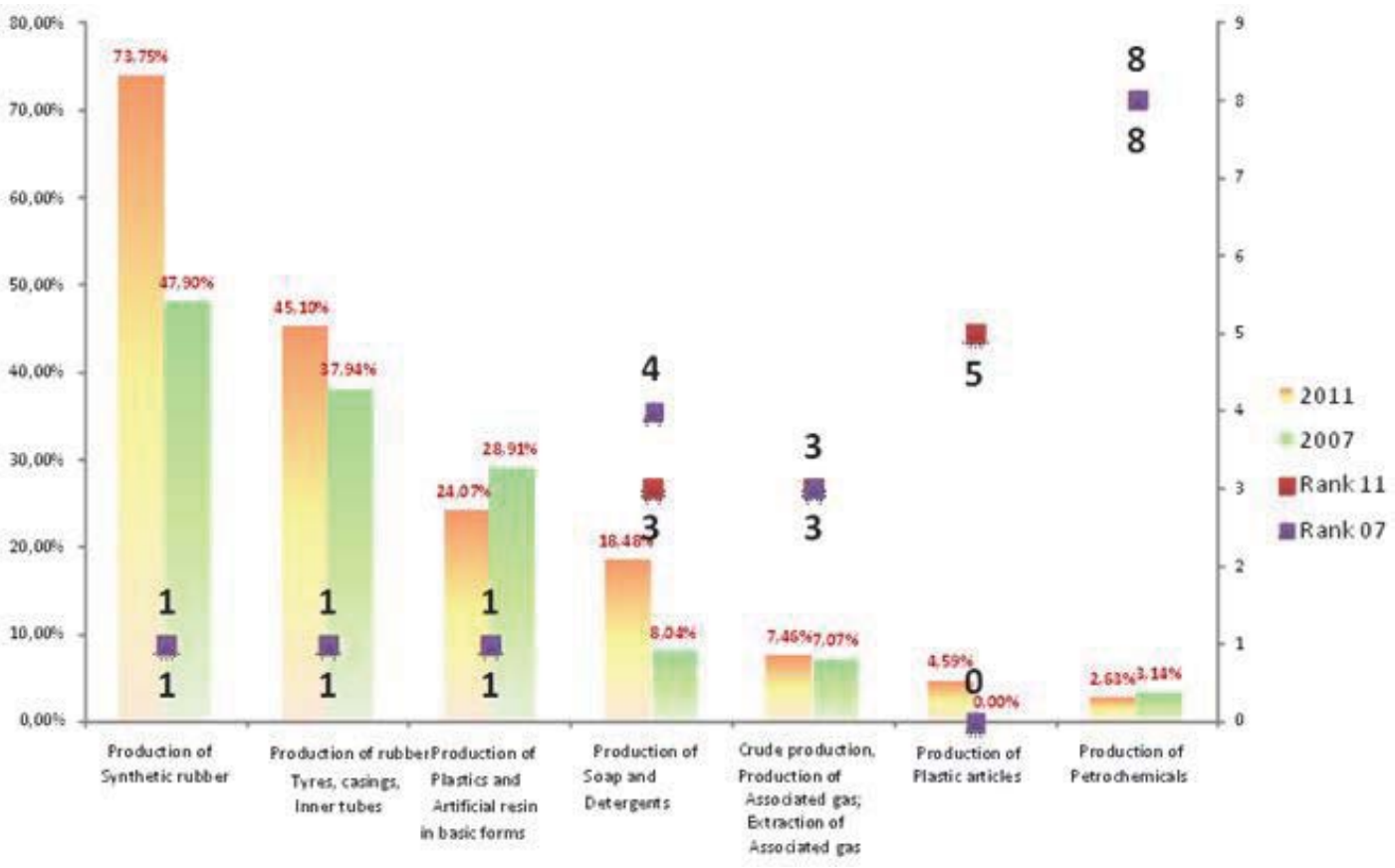

Fig 4. Dynamics of market shares of economic activity types in petrochemical cluster of the Republic of Tatarstan in 2007-2011 


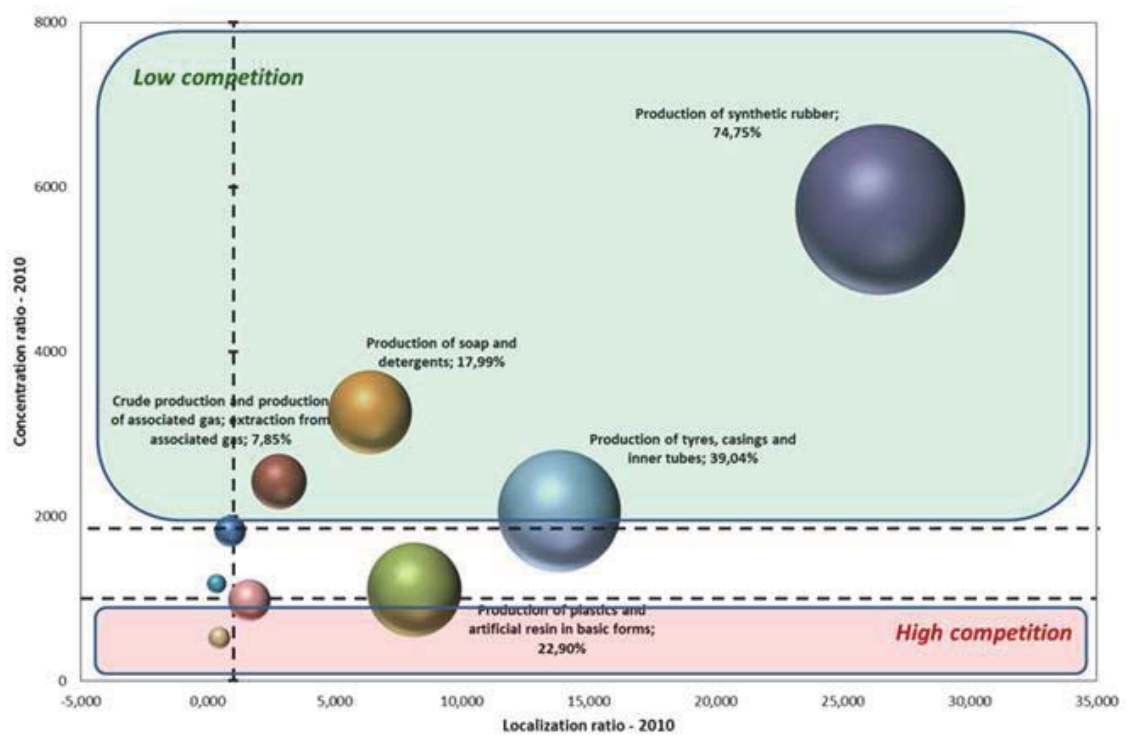

Fig. 5. Level of competition at markets of industrial profile of the Republic of Tatarstan at the beginning of 2011 (Petrochemical cluster)

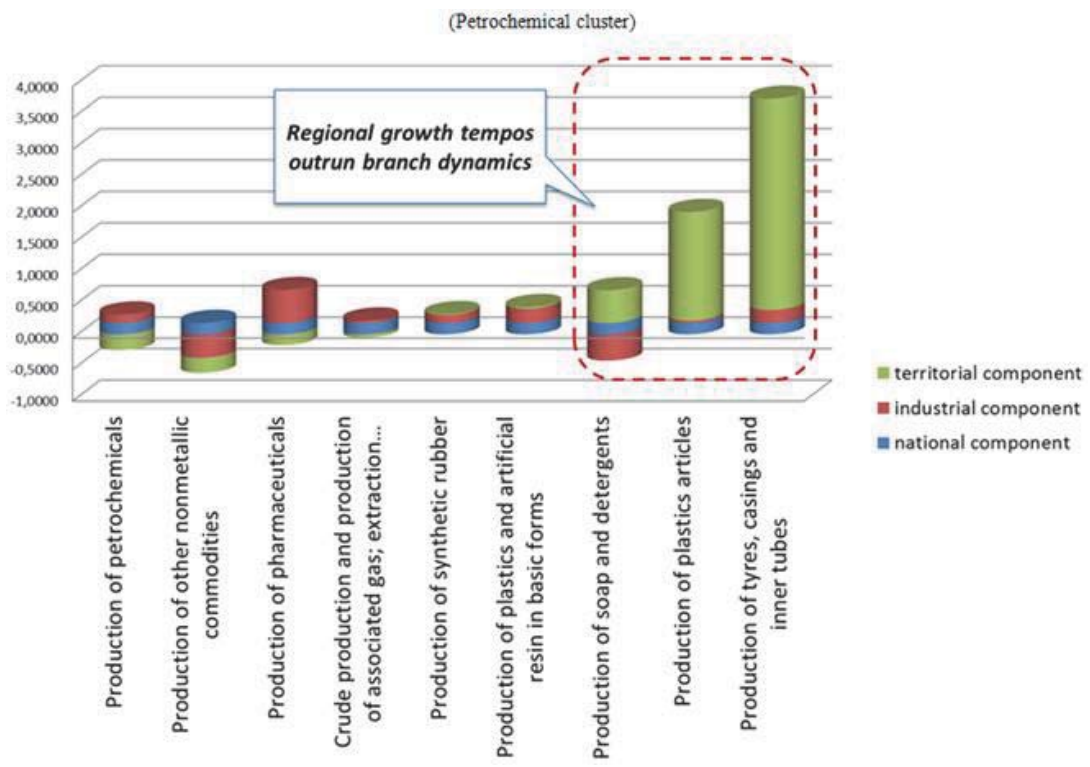

Fig. 6. Structural decomposition of capacity gain of turnover in the Republic of Tatarstan for 2007-2011 by types of economic activity

Dynamics of market shares of Tatarstan petrochemical cluster types of economic activity in $2005-2010$ was not so active in the following types of economic activity: production of plastics and synthetic resin, production of artificial rubber, production of rubber tires, tire casings and inner tubes. Market shares of such types of economic activity, as extraction of crude oil and oil (associated gas), production of petroleum products were not substantially changed.

According to the results of comparing the competition level on Tatarstan petroleum market in the beginning of 2007 and 2011, one can observe that the competition level of the majority of types of economic activity of petrochemical cluster was changed in 2011 and they started to lose their positions: extraction of crude oil and oil (associated) gas, production of rubber tires, tire casings and inner tubes, production of soap and detergents, production of plastics and synthetic resin in primary forms, production of petroleum products (Fig. 5). Only production of artificial rubber has been occupying a more confident position in given years. 
Analysis of turnover capacity dynamics in 2007 - 2011 by method of structural decomposition of growth rates brought the following results (Fig. 6).

Despite a crisis in 2008-2009 the positive macroeconomics dynamics of 2010-2011 ensured capacity gain of the reviewed types of economic activity equal to $18,06 \%$ (NS component). With consideration for industrial scale the maximum effect was achieved in crude production, production of associated gas; production of petrochemicals; production of synthetic rubber; production of plastics and artificial resin in basic forms.

The biggest branch rate of growth (IS component) for 2008-2010 years (running ahead of macroeconomic dynamics) was demonstrated by:

- Production of pharmaceuticals (growth 52. 37\%);

- Production of plastics and artificial resin in basic forms (22.8\%);

- Production of rubber tyres, casings and inner tubes (20.83\%).

Herewith more than a half of reviewed types of production had negative growth of turnover capacity. The significant decrease among profile types of economic activity was registered only in production of soap and detergents (-41.67\%);

From the point of competitiveness evaluation those types of economic activity which regional tempo of growth run ahead of the branch (IS component) and macroeconomic (NS component) dynamics are of specific interest. Such productions are (fig. 6):

- Production of rubber tyres, casings and inner tubes (the regional growth is 3,3589 while the branch growth is 0,2083);

- Production of plastics (1,7254 and 0,0384 correspondingly);

- Production of soap and detergents (0,5199 and -0,4167 correspondingly).

Table 1. Share of economic activity types of the Republic of Tatarstan in gross industrial-based turnover, \%,

\begin{tabular}{|c|l|c|c|c|c|c|c|}
\hline $\begin{array}{c}\text { Position of } \\
\text { region until } \\
\mathbf{2 0 1 1}\end{array}$ & Regions & $\mathbf{2 0 1 1}$ & $\mathbf{2 0 1 0}$ & $\mathbf{2 0 0 9}$ & $\mathbf{2 0 0 8}$ & $\mathbf{2 0 0 7}$ & $\begin{array}{c}\text { Change in 2011 in } \\
\text { comparison with 2007 }\end{array}$ \\
\hline 1 & Production of synthetic rubber & $73,75 \%$ & $74,75 \%$ & $72,84 \%$ & $74,07 \%$ & $47,90 \%$ & $25,85 \%$ \\
\hline 1 & $\begin{array}{l}\text { Production of rubber tyres, tyre casings } \\
\text { and inner tubes }\end{array}$ & $\mathbf{4 5 , 1 0 \%}$ & $\mathbf{3 9 , 0 4 \%}$ & $\mathbf{4 3 , 6 5 \%}$ & $11,42 \%$ & $37,94 \%$ & $7,16 \%$ \\
\hline 1 & Production of plastics and artificial resin & $24,07 \%$ & $22,90 \%$ & $18,12 \%$ & $22,53 \%$ & $28,91 \%$ & $-4,84 \%$ \\
\hline 3 & Production of crude and associated gas & $7,46 \%$ & $7,85 \%$ & $8,78 \%$ & $8,19 \%$ & $7,07 \%$ & $0,38 \%$ \\
\hline 5 & Production of plastics articles & $4,59 \%$ & $4,56 \%$ & $3,34 \%$ & $1,89 \%$ & $2,70 \%$ & $1,89 \%$ \\
\hline 8 & Production of petrochemicals & $2,63 \%$ & $2,42 \%$ & $2,33 \%$ & $2,99 \%$ & $3,14 \%$ & $-0,51 \%$ \\
\hline
\end{tabular}

It should be emphasized that almost all types of economic activity in the industrial profile of the Republic of Tatarstan have shown positive regional dynamics. Only crude production and production of associated gas are exception as their RS components were negative $(-0,0507)$ at positive branch growth. Considering the industrial profile of the region in long term one may turn attention to the significant lag in recovery tempos of economic indicators of the following types of economic activity (negative value of regional RS components):

- Production of petrochemicals (-0.2472);

- Production of other nonmetallic mineral commodities $(-0.2377)$;

- Production of pharmaceuticals (-0.1682).

Despite negative regional dynamics two types of economic activity (production of petrochemicals and production of pharmaceuticals) demonstrate positive branch growth (IS components) (0.1333 and 0.5237 correspondingly).

\section{Conclusion}

In such a manner the conducted structural analysis of dynamics has revealed some negative factors which influenced on the competitive position of the industrial complex of the Republic of Tatarstan. First of all, branch tempos of turnover growth in almost all productions which compose the industrial profile of Tatarstan turned out to be negative or did not exceed industry average dynamics (NS component). It witnesses the high dependence of such types of economic activity on crisis events in Russian economy of 2008-2009. The exceptions are production of plastics and synthetic rubber in basic forms, production of rubber tyres, casings and inner tubes; dynamics of their turnover exceeded macroeconomic indicators. Secondly, regional components of only five profile types of economic activity (production of rubber tyres, 
casings, inner tubes, production of plastics articles, production of soap and detergents) run ahead of branch and macroeconomic growth tempos. Notably, only production of rubber tyres has influence on Tatarstan economy. Respectively, profile types of activity have not so evident competitive edges or the region has limited opportunities of influence on the sources of their formation.

In the meantime the highest regional gain was demonstrated by productions with fair low localization in capacity. By keeping such tendencies in long term perspectives these productions may be considered as a target investment portfolio which can provide gradual substitution of the present industrial profile and forming potential of strategic growth of the Republic's economy.

\section{References}

Nerbrand, Fredrik. 2013. "Age shall weary them. The productivity challenge of the rich world's demography." The Economist. May 11. http://www.economist.com/news/finance-and-economics/21577414-productivity-challenge-rich-worlds-demography-age-shallweary-them

Shirov, Alexey, Gusev, Michael, Yantovskiy Arkady and Potapenko, Victor. 2012. "Long-term development of Russian economy and issue of labour resources efficiency." Issues of forecasting 1: 21-37.

Grabar, Yakov. 2013. "Labour efficiency: use your intelligence, do not work till night." RBC. March 11. http://top.rbc.ru/economics/ 27/03/2013/850963.shtml

Granberg, Alexandr and Mikheeva, Natalya. 2009. "Influence of world crisis on strategy of spatial social-economic development of the Russian Federation." Region: economics and sociology. 4: 34-41.

Gafurov, Ilshat, Safiullin, Marat and Safiullin, Azat. 2012. Analysis of structural gaps of competitiveness in petrochemical cluster of the Republic of Tatarstan. Kazan: Kazan University.

Safiullin, Marat and Safiullin, Azat. 2011. Regional competitive advantages (by the example of Republic of Tatarstan). - Kazan: Kazan University.

Safiullin, Azat. 2011. Competitive Positions (territorial-economic level). Munich: LAP LAMBERT Academic Publishing GmbH \& Co. KG.

Novosyolova, Olga. 2011. "Interregional exchange as a development factor of cluster structure of regional economics." Issues of forecasting. 3: 23-29.

Brown, David and Earle James. 2008. Employment Reallocation and Productivity Growth in Transition: an International; Comparative Analysis. UK, Edinburgh: Upjohn University for Employment Research, February.

Safiullin, M.R., Safiullin, A.R., Ermolaeva, P.O., Noskova, E.P. "Interdisciplinary approach to the analysis of the competiteveness types of the economic activities based on the example of the oil and gas industry (Republic of Tatarstan case)". Middle East Journal of Scientific Research, No18 (1), pp. 42-49.

Safiullin, M.R., Safiullin, N.Z., Saipullaev, U.A., Safiullin, L.N. "Estimation of competitiveness of russian regions by economic activity". Middle East Journal of Scientific Research, Vol. 16, Iss. 10, 2013, pp. 1413-1418.

Parr, J.B. "The Regional Economy, Spatial Structure and Regional Urban Systems". Regional Studies. 2013. 